\title{
Consideraciones sobre la transmisión de la Propiedad Inmueble
}

\author{
Por ANTONIO VALDEZ CALLE
}

\section{I.-Generalidades.}

1.-Problema capital ha sido y es en el derecho el de la transmisión de la propiedad referida especialmente a los inmuebles. Juegan en él factores regidos por principios diferentes, esto es: la teoría general de las obligaciones y las normas propias de los derechos reales.

Como se trata de conjugar armónicamente instituciones que presentan características diferentes, las soluciones que se han dado y que actualmente imperan en el mundo jurídico no son una complemento de la otra, sino que son campos independientes que se excluyen. Nos referimos al sistema francés y al sistema alemán.

2.-Para el primero, las relaciones jurídicas del hombre con la cosa son de derecho privado; la intervención del Estado para la garantía y seguridad de tales relaciones es algo que casi no debe ser tomado en cuenta. En cambio, para el derecho alemón, esas mismas relaciones son de derecho público; los poderes públicos y en su nombre las autoridades deben intervenir en la constitución, modificación y extinción de aquellas relaciones.

Entonces pues, es lógico que para el sistema del Código Napoleón la propiedad territorial se transmita por el mero consentimiento de las partes. Los ccntratos reales son en sí, productores de una obligación de dar que se reputa ejecutada en cuanto aparece; su nacimiento es la señal de su extinción. Todo se reduce a una operación mentalmente ejecutada. La tradi ción que puede o no venir después del pacto, es un hecho que no tiene la virtud de hacer propietario al adquirente, sino simplemente de ponerlo en aptitud de servirse de la cosa.

E1 sistema del Código Alemán, al contrario, propugna que nadie puede ostentar el título de propietario si nó ha obtenido previamente la confirma. ción o investidura de tal derecho, previo un examen minucioso de los an. tecedentes.

Dice el Art. 925 de ese código: "El acuerdo del vendedor y del comprador, necesario según el Art. 813 para la transmisión de la propiedad de un predio, deberá declararse en la oficina del Registro en presencia simultánea de las dos partes". 
"Como necesario complemento de las disposiciones generales sobre la adquisición legal de los derechos sobre inmuebles - nos dice la Exposición de Motivos del código alemán- exige el Código que para la transmisión de los inmuebles se haga declaración simultánea por ambas partes en el registro, a las cuales se presenta así el cambio de propiedad como directa consecuencia de tal acto, que es a la vez garantía contra un paso precipitado y aleja el peligro de que el acuerdo esté en contradicción con el contenido del registro"... o sea pues que el derecho real sólo se transmite cuan. do ha intervenido el Estado.

Posteriormente, la ley francesa de 26 de marzo de 1855 creó la necesidad de transcribir en el Registro todo derecho real para que pueda ser opuesto a terceros. Quedó así conformado el actual sistema que es también el de nuestro Código Civil de 1936.

3.-El Art. 1172 del Código Civil de 1936, dice: "La sola obligación de dar una cosa inmueble determinada, hace al acreedor propietario de élla, salvo pacto en contrario". El simple acuerdo, sin ningún formalismo como podría ser el registro, desplaza la propiedad. Pero como a la vez existe al régimen de la inscripción -no obligatorio para nosotros- que aparentemen. te podría ser contradictoria con el principio contenido en el Art. 1172, tene. mos que aceptar la diferencia que hay entre la transmisión de la propiedad sólo entre las partes y la transmisión de la propiedad frente a terceros.

4.-El acuerdo de voluntades desplaza la propiedad solo entre las partes que intervienen en el contrato. En cambio, frente a los terceros no ha habido desplazamiento de la propiedad. La institución del registro exige que para que la propiedad se considere transmitida frente a terceros, es necescrio que se inscriba la traslación del dominio. Hay pues dos tiempos sucesivos e independientes: el acuerdo, que solo tiene efecto entre las partes; y la inscripción que dá valor al derecho frente a terceros.

5.-Como se ha dicho anteriormente, el régimen del registro es opcional Y no obligatorio. Si una propiedad no está inscrita, el solo acuerdo hace propietario al comprador; éste ya no es el titular del derecho únicamente frente al comprador, sino también trente a la comunidad, aunque repugne que un acto de voluntad constituya un derecho real.

6.-En cambio, si el contrato ha versado sobre una propiedad inscrita y el comprador ha omitido registrar su derecho, puede correr una serie de riesgos no solo por parte del vendedor o aún de la misma comunidad que ya respeta un hecho amparado en un principio legal, sino de parte de un tercero que puede recibir del mismo vendedor- que onte el comprador ya no es propietario de la cosa y que de hecho ante la comunidad tampoco lo es, pero que frente a la institución del registro continúa siéndolo- la misma co$s \propto$ que había vendido $\alpha$ otro.

El derecho de este segundo comprador estará amparado por los ortículo 1052 y 1174 del Código Civil. Contra ese acto inscrito otorgaclo por persona que en el registro aparecía con derecho para éllo, no habrá medio de hacerlo invalidar aunque se anule el derecho del otorgante en virtud de título anterior no inscrito o de causas que no resulten claramente del mismo registro. Este derecho tan firme tendrá prioridad sobre cualquier otro que pretenda alegarse y que no haya sido inscrito. 
El primer comprador nada podrá hacer para recuperar el bien que se transmitió al segundo. Tendrá si acción personal contra el vendedor para reclamar el valor de la cosa si es que pactó el precio del inmueble, y a una indemnización de daños y perjuicios, según el caso. Los otros principios del derecho de las obligaciones no podrón ser aplicados; todos se estrellarán contra la institución del registro que debe amparar ante todo a quienes de buena fé contratán con la garantía de élla. La ley le dá esa fuerza porque debe proteger $\mathrm{y}$ defender al instituto de derecho público creado con un fin social.

\section{II.-El contrato y la obligación.}

7.-Nuestro código civil en el libro tercero sólo trata de İa adquisición de la propiedad por modos originarios, esto es, la accesión y la prescripción; nosotros tendremos que referimos ahora $\alpha$ uno de los derivativos, $\alpha$ la en $\alpha$ jenación, que se realiza por medio del contrato de compra-venta.

Para Pothier (1), el contrato es una especie de convención que tiene por objeto algo más que formar un compromiso. Dice que debe definirse como una convención por la cual dos partes recíprocamente, o solo una de las dos, prometen y se obligan para con la otra a darle alguna cosa, o a hacer o no hacer tal cosa. Encierra pues el contrato el concurso de voluntad de dos personas, de las cuales, una promete alguna cosa a la otra, y la otra acepta la promesa que se le ha hecho.

Tienen por objeto: o cosas que una de las partes contratantes estipula que se hará, y que la otra promete darle; o bien alguna cosa que una de las partes contratantes estipula que hará, o que no hará, y que la otra promete hacer o no hacer (2).

8.-Dice el Art. 1383 del Código Civil de 1936: "Por lat compra-venta el vendedor se obliga a transferir la propiedad de una cosa y el comprador $\alpha$ pagar el precio en dinero".

Celebrado el contrato nace, de él una obligación.

9.-La palabra obligación, según Giorgi (3), atendida a su etimología, contiene clarísima la idea de sujección, de ligamen porque indudablemente liga $\mathrm{o}$ ata al deudor, constrinéndolo a desplegar parte de su actividad en beneficio del acreedor. Hay pues un vínculo de carácter jurídico entre dos o más personas determinadas, en virtud del cual, una o varias de éllas quedan sujetas respecto $\alpha$ otra $u$ otras $\alpha$ hacer o no hacer alguna cosa.

10.-El contrato no ha hecho nacer un nexum material como para el derecho romano primitivo, en el que se desconocía el concepto abstracto de la obligación, sino que ha creado un vínculo de derecho - que ya era concebido en el derecho romano clásico- pero que se ejecuta ipso-facto para el actual sistema francés que es también el de nuestro código.

La transmisión de la propiedad no se hacía en Roma por medio de los contratos; éstos solo tenían por misión engendrar una obligación. Y cuan-

( I) R. J. Pothier.-Tratado de las Obligaciones.-p. 12 y 13.

(2) R. J. Pothier.- op. cit. póg. 40.

(3) G. Giorgi. - Tratedo de las Obligaciones.-T. I. pág. 11. 
do la obligación consistía para el deudor en transmitir la propiedad, esta transmisión procedía de una operación simultánea o ulterior, de la mancipa. tio para las res mancipi, de la tradición para las res nec mancipi y también de la in jure cesio para unas y otras (4).

11.- Para nuestro sistema, el contrato no solo ha sido fuente de una obligación sino que ha transmitido la propiedad; esta se ha convertido en un efecto tan directo e inmediato del contrato como la misma creación de obligaciones. El comprador ha devenido propietario de la cosa al mismo tiempo que acreedor del enajenante (5). La obligación de transmitir la propiedad convenida entre las partes, ha sido ejecutada al mismo tiempo en que se formó.

"Vender o donar es enajenar; comprar o aceptar una donación es adquirir, en el acto" (6). Los contratos son siempre productores de una obligación de dar que se reputa ejecutada en cuanto aparece.

12.-Este vínculo de derecho, esta sola obligación de dar una cosa inmueble determinada ha hecho al acreedor propietario de élla - salvo pacto en contrario- sin necesidad de ningún formalismo (Ârt. 1172 del Código Civil). No ha sido necesaria la tradición romana para poner al comprador en po. sesión del bien y que desde ese momento éste se considere propiețario, ni tampoco ha sido necesaria la clóusula de desposesión-posesión que existió en el derecho francés anterior al Código Napoleón. El solo acuerdo de las partes ha bastado para que se efectúe el cambio de propietorios.

13.-El contrato ha creado una obligación que por referirse $a$ un inmueble ha hecho automáticamente propietario al acreedor del anterior titular. Por un lado, el contrato ha trasladado la propiedad, pero por otro, el vínculo jurídico que ha nacido entre las partes no se considerará cumplido mientras el vendedor no haga entrega de la cosa debida.

Y mientras la entrega no se haya efectuado "no se entenderá efectuado el pago, que exige además, que se haya cumplido por completo la prestación en que la obligación consiste" (Art. 1234 dsl Código Civil).

Efectuadas todas las formalidades se extingue el vínculo obligacional entre las partes y solo subsiste el nuevo derecho real del acreedor que por el simple acuerdo se convirtió en propietario y que detenta un derecho oponible a todos (6).

(4) Colin y Capitant. - Derecho Civil. T. 2 V. II. pǻg. 100e.

(5) Planiol $y$ Ripert.- Tratada de Derecho Civil. Vol. III. pág. 534.

(6) Josserand.- Der. Civ. T. I.- V. 2.- pág. 262.

Véase ađemás:

A. G. Cornejo. - Código Civil, T. II. Vol. I. pág. 74.

León Barandiarán. - Comentarios al C.C. Peruano. T. II. pág. 7.

Badani R.- Curso de Obligaciones. pág. 39. 


\section{III. -El Registro.}

14.-En la doctrina moderna el formalismo vá apareciendo ya con una finalidad de garantía, ya para facilitar el comercio jurídico y crear signos de valor fó́cilmente transmisibles. Se advierte una tendencia a restringir la sigrificación de la voluntad en los actos jurídicos y por lo tanto en las obligaciones que de éllo nacen. Para muchos autores, las consecuencias de un acto jurídico no resultan de la voluntad expresada en él sino de la ordenación del derecho objetivo (7).

De otro lado, como dice Planiol (8), Ia transmisión convencional de la propiedad inmueble no puede ser defendida sin exponerse a los peores inconvenientes, salvo si se le respalda con un sistema de publicidad destinado a dar a conocer a los terceros las transmisiones de propiedad así como las constituciones de derechos reales inmuebles; de donde resulta que fuera de la publicidad, no puede haber seguridad en las transacciones ni solidez en la organización del crédito hipotecario.

15.-Aunque la transmisión de los derechos por la sola convención tiene la ventaja de la sencillez, la clandestinidad con que pueden proceder los vendedores es un serio inconveniente que debe ser salvado de alguna manera, porque los terceros están expuestos a tratar con quien ya no es propietario de la cosa. "Este peligro no existiría - dice Colin y Capitant (9)o sería menor si se hubiese conservado el sistema romano para transmisión de la propiedad".

También debemos de tener en cuenta que el derecho real que es oponible a la comunidad entera, no puede nacer y manifestarse si dicha comunidad lo ignora (10).

Es pues necesario que en cualquier momento pueda identificarse al verdadero propietario, lo que solo podrá obtenerse con un régimen de publicidad.

16.-El registro puede tener como finalidad la simple publicidad de los de rechos reales, para que puedan ser conocidos por todos.

El sistema alemán, en cambio, persigue con el registro, además de la publicidad, el dar seguridad al comercio de inmuebles; de allí que señalen como condiciones de la institución que la matriculación constituya una prueba concluyente del derecho inscrito y que dé legalidad absoluta $\alpha$ la titulación del inmueble. Antes de la inscripción la propiedad no sale del poder del propietario y aún cuando haya un contrato auténtico de transferencia éste solo conferirá un derecho meramente personal al adquirente.

17.-Ese régimen de publicidad al que la ley dớ el móximo de valor, para el sistema francés - que es el nuestro- no destruye el principio de la transmisión de la propiedad por el simple acuerdo de las partes, pues, la venta sigue siendo en principio translativa de la propiedad por si misma.

(7) Colin y Capitant.- op. cit. T. 3. p. 12.

(8) Planiol y Ripert. - op. cit. T. III. p. 542.

(9) Colin Y Capitant. - op. cit. T. 2. pág. 1015.

(10) Josserand. - op. cit. pág. 366. 
El fin de la institución del registro es entonces asegurar la publicidad de las transmisiones de la propiedad inmobiliaria; de llevar a conocimiento del público los actos translativos; no es pues ninguna consideración de las partes entre sí. Para las partes la propiedad se ha transmitido por el hecho mismo del simple acuerdo. La obligación que nació, se ejecutó en el mismo momento de su aparición: "su nacimiento es la señal de su extinción" (11).

18.-El ragistro ha sico creado para los terceros; para éllos la propiedad solo se desplaza desde el momento en que la inscripción se efectúa. Para los terceros, mientras no se haya inscrito el derecho del nuevo propietario, el vendedor sigue siendo el titular del derecho; pero como se dice más arriba, solo para los terceros, porque frente al comprador, el vendedor ya ha dejado de ser el propietario. Hay pues, dos campos: el de las partes entre sí, entre quienes vale solo el simple actierdo, y el de los terceros, para quienes sólo la inscripción señalará ciertamente al propietario. "Los contratos tienen fuerza de ley entre las partes. No producen efecto respecto a terceros" (12).

19.-Terceros no son todos los que no sean las partes. "Son los verdaderamente extraños a los contratantes" (13). No lo son sus causahabientes.

En caso de que el vendedor haya enajenado el mismo bien a varias personas y que se haya dejado de inscribir el título, estarán beneficiados con el nombre de terceros "aquellos a quienes después de haber pactado con un propietario se les oponen enajenaciones o constituciones de derechos reales convenidas con otras personas por ese mismo propietario, sin haberse hecho públicas... y que no sean responsables de la falta de transcripción ni culpables de concertarse fraudulentamente con el vendedor" (14).

Entonces pues, "entre causahabientes de un mismo vendedor, triunfu aquel que haya inscrito primero su título, porque la eficacia de sus derechos es el premio de la celeridad" (15). Consiguientemente la preferencia pues no se rige por la fecha de los títulos de adquisición sino por la prioridad de la inscripción.

Para ser tercero es necesario: $\alpha$ ).-Haber adquirido un derecho sobre el inmueble; b)-Haber conservado este derecho conforme a ley; c)-Haber adquirido el derecho del enajenante: $y$ d)-que la falta de inscripción no sea imputable al mismo que quiere invocarla (16).

20.--Para Josserand y Colin y Capitant, hay que prescindir de la buena o mala fe del tercero en caso de que el vendedor ya haya transmitido la propiedad a otro, porque bastan con las condiciones que se han indicado más arriba. Dicen que aunque el tercero haya conocido la venta anterior, triunfará sobre el primitivo comprador si es que inscribió primero su derecho. Josserand sostiene que "la característica del régimen de publicidad es funcionar mecánicamente sin atender a la moralidad de las partes" (17). Apli-

(11) Josserand. - op. cit. pág. 264.

(12) Colin y Capitant.- op. cit. T. 3. pág. 626.

(13) Colin Y Capitant.- loc. cit. pág. 640.

(14) Planiol y Ripert.- op. cit. T. III. pág. 562.

(15) Planiol y Ripert.- loc. cit. pág. 562.

(16) Colin y Capitant. - op cit. 2. pág. 1046.

(17) Josserand.- op. cit. T. 1. Vol. 2. pág. 287. 
can, para sostener esta posición, el Art. 1071 del Código Napoleón que dice: "La falta de transcripción no podrá ser suplida ni considerarse disculpada por el conocimiento que los acreedores o que los terceros adquirentes hayan podido tener de la disposición por otros medios que no sean los de la transcripción".

Pero los autores franceses a que nos hemos referido hacen un gran alto cuando el segundo adquirente se ha concertado fraudulentamente con el vendedor para despojar al primer comprador. Dice Planiol (18) que en ese caso, el Art. $3^{\circ}$ de la Ley de 1855 no puede ser aplicado, de acuerdo con el principio fraus omnia corrumpit, no porque el segundo haya cometido un delito $\mathrm{y}$ como sanción al mismo sino porque el traude hace inaplicable la regla del Art. $3^{\circ}$ ya citado.

Para Josserand (19) la regla de que hay que prescindir de la buena o mala fe de las partes tiene un límite: el fraude, y entiende por él la voluntad de sacar la ley de su campo de aplicación normal; en concreto, la voluntad de poner la transcripción al servicio de un complot urdido entre el enajenador $\mathrm{y}$ el segundo adquirente. Agrega que la transcripción así falseada pierde su eficacia habitual porque ha existido un abuso de élla y por tal causa, el segundo que de acuerdo con el enajenante quiso ganar en velocidad al primero, aunque haya llegado primero a la meta, será descalificado, porque se habró servido deslealmente de una institución regular.

\section{IV.--Comentario al sistema del Código Civil Peruano}

21.-Sabemos que los derechos patrimoniales, según la diversa especie de bienes sobre que recaen, pueden subdividirse en derechos reales y en derecho de obligaciones; los primeros crean una relación entre persona y cosa, y los segundos crean una relación entre persona y persona.

Son materia de los derechos reales los bienes consistentes en las cosas consideradas como útiles en sí, es decir, en su aptitud para servir por sí solas a ciertas necesidades nuestras. En combio, están dentro del campo de las obligaciones aquellos bienes que consisten en actos de otras personas; es decir, en las prestaciones ajenas en cuanto nos pueden proporcionar alguna utilidad susceptible de ser valuada en dinero.

22.-La propiedad subsiste plena y perfecta sin necesidad de otras personas diversas del propietario. La obligación no puede subsistir sin la persona de un deudor determinado, al que se restringe la relación jurídica, a quien sólo se puede reclamar su cumplimiento y el que únicamente puede violorla (20).

A los derechos reales corresponde una obligación negativa que pesa sobre todos: la obligación de respetarlos, de abstenerse de turbar su ejercicio. Y es evidente que una obligación de ésta índole no puede razonablemente derivar su existencia de un hecho relativo a dos personas determinadas e ignorado de los terceros (21).

(18) Planiol y Ripert.- op. cit. T. III. pág. 565.

(19) Josserand.- op. cit. T. I. Vol. 2. pág. 287.

(20) G. Giorgi.- op. cit. T. I. pág. 2.

(21) Actas de la Comisión Reformadora.-Fasc. V. pág. 29. 
23.-La distinción entre los contratantes y los terceros desde el punto de vista de ia transmisión de la propiedad contradice, así mismo, la naturaleza del derecho real, pues como hemos visto anteriormente éste es un derecho absoluto que puede hacerse valer contra todos. Un derecho real que no puede oponerse a terceros, un derecho real relativo constituye por lo tanto un contrasentido. De allí que para transmitir la propiedad de una cosa entre los contratantes y respecto de terceros, no basta la mera voluntad de las par. tes sino que es necesario la tradición tratóndose de los muebles $\mathrm{y}$ la inscripción tratóndose de los inmuebles (22).

El tratadista J. Morell y Terry, respondiéndose a la pregunta de cuóndo se adquiere verdadero derecho real sobre el objeto transmitido dice: "El momento en que cambia de sujeto el derecho real, tiene que ser aquel en qua el hecho se hace público en forma tal que puede y debe presumirse que ha llegado o ha podido llegar a conocimiento de todos. Ese momento es realmente el de la inscripción; luego la inscripción representa la adquisición de la propiedad inmueble y de todos los derechos reales sobre la misma. Todo existe o deja de existir cuando se hace público o conocido por la masa social, esto es cuando se inscribe.

Luego la inscripción, por su propia naturaleza, debe ser considerada como el único modo de adquirir, de conservar y de perder el dominio de los bienes inmuebles y de los derechos reales constituídos sobre los mismos"... (23).

24.-Este sistema de la inscripción armoniza, además, con el concepto moderno de la propiedad, esto es, en relación con la función sccial que debe desempeñar, siendo consiguientemente necesaria la intervención del Estado, supremo regulador, en los actos que controlen su nacimiento o su extinción.

25.-Pero además de estas razones tenemos otras que para Giorgi (24) nacen del error de los codificadores franceses quienes al decir que la propiedad se adquiere por efecto de las obligaciones han desnaturalizado el derecho de obligación $y$ lo han reducido a casi un modo de adquirir y transmitir la propiedad.

Para el derecho romano no era posible esta confusión entre derechos de crédito y derechos reales por ser diversos los medios de crearlos y transmitirlos. Pero en el derecho moderno - que sigue al francés- que atribuye a la voluntad humana una potestad igual para ambas clases de derechos y que ha establecido que los derechos reales adquieren vida y se transmiten por el solo consentimiento al igual que los de crédito, ha hecho que no sea posible diferenciar la naturaleza de un derecho del modo por virtud del cual se constituyó, lo que ha traído coma consecuencia la confusión más deplorable entre derechos reales y derechos de crédito.

26.-De todo esto nace ese principio ton forzado en nuestro sistema de que el vendedor que transmite la propiedad $\alpha$ un primer adquirente puede, habiendo dejado de ser propietario, vender el mismo bien a un segundo, bajo el amparo del registro.

(22) Actas de la Com. Ref.- Fasc. V. pág. 30.

(23) Ibid. pág. 24.

(24) G. Giorgi.- op. cit. T. I. pág. 3. 
Si el acuerdo desplazó el derecho real, la inscripción no puede ser otra cosa que la confirmación sacramental del Estado sobre un acto que tiene pleno valor merced al principio de que la sola obligación de entregar una cosa inmueble determinada hace al acreedor propietario de élla. El registro no puede pues dentro de este sistema y siguiendo a la lógica, establecer otro campo independiente, y según nuestra ley, de más valor que el del simple acuerdo, para sembrar un principio contradictorio que nunca se resolverá hasta que no se modifique $\epsilon \mathrm{l}$ sistema y se consiga que el registro sea lo que debe ser: esto es, quien transmita realmente la propiedad y dé un carácter de inatacable al título que él emita. Mientras el registro continúe siendo un notificador que indebidamente dispone de facultades que corresponden al registro pero dentro de la concepción alemana, no podrá llegarse $\alpha$ una solución saludable en los conflictos que se presentan.

27.-Eso en el campo del debe ser ideal. Pero ante la realidad mucho pesan todavía las palabras del doctor Olaechea en el seno de la Comisión Reformadora (25) que nos hacen pensar con el ilustre ponente que aún no estamos preparados para adoptar plenamente un sistema que puede ser todo perfección.

Probablemente el mejor momento para pensar en esta reforma sería aquel en que se estudiase o resolviese la reforma de la ley orgánica del poder judicial, haciendo realmente independiente a la administración de justicia. El registro tendría que ser incorporado o depender en la selección de personal y demás cuestiones técnicas del poder judicial ya independiente y decorosamente pagado. Contando con un eficiente factor personal podría entonces procederse a la reforma del sistema.

Seguramente que lo más indicado no habría de ser el paso total al sistema único de la propiedad inscrita porque todavía subsistirían muchas de las razones dadas por Olaechea y porque en pueblos como el nuestro cuesta mucho salir de lo rutinario. Además, como dice Bordeaux "el principio absoluto de la inscripción no es realizable en la práctica" (26).

Tendríamos que adoptar la fórmula transaccional que propuso el doctor Oliveira y que es: "La transmisión de la propiedad, por efecto de los contratos, se verifica: respecto de los muebles por la tradición; respecto de los inmuebles. ror la escritura pública; y respecto de los inmuebles inscritos; por la inscripción en el registro de la escritura pública correspondiente" (27).

\footnotetext{
(25) Actas de la Com. Reformadora.- Fasc. V. pág. 68.

(26) Ibid. pág. 60.

(27) Ibid. pág. 59.
} 